\title{
PENERAPAN PORTOFOLIO INVESTASI ASET PROGAM DANA PENSIUN PADA OPTIMALISASI EXPECTED RETURN
}

\author{
Dwi Jaya Kirana \\ Universitas Pembangunan Nasional Veteran Jakarta \\ Email: dwijayakirana@upnvj.ac.id
}

\section{KETERANGAN ARTIKEL}

Riwayat Artikel

Diterima: 1 November 2019

Direvisi: 15 November 2019

Disetujui: 1 Desember 2019

Klasifikasi JEL

G11, M41

Keywords: Pension Fund Asset, Allocation, Expected Return

Kata kunci: Alokasi Aset Progam Dana Pensiun, Expected Return, Imbalan Pasti dan Iuran Pasti

\section{ABSTRACT}

This study aims to examine the implementation of pension fund asset allocation to equity, debt securities, time deposits, real estate, and others in determining expected returns. The samples used in this study are all listed companies that disclose the allocation of pension fund assets in 2016 -2018. The total sample is 93 companies. The analysis of this study uses multiple regression and statistical analysis of the Financial Services Authority (OJK). The results of the study show that all the variables of the allocation of pension fund assets have a significant effect on an expected return unless the other variables OTHER have a significant negative effect on expected return. The allocation of the defined benefit program assets and the defined contribution of the employer pension fund (DPPK) tend to be higher in equity and debt than the defined contribution assets of the Financial Institution Pension Fund (DPLK) more to deposits with fixed yields.

\begin{abstract}
ABSTRAK
Penelitian ini bertujuan untuk menguji penerapan alokasi aset progam dana pensiun pada ekuitas, surat hutang, deposito berjangka, real estate, dan lainnya dalam menetapkan expected return. Sampel yang digunakan dalam penelitian ini adalah semua perusahaan listed yang mengungkapkan alokasi aset progam dana pensiun selama tahun 2016-2018. Total sampel ada 93 perusahaan. Analisis penelitian ini menggunakan regresi berganda dan analisis data statistik Otoritas Jasa Keuangan (OJK). Hasil Penelitian menunjukkan semua variabel alokasi aset progam dana pensiun berpengaruh signifikan terhadap expected return kecuali variabel lainnya OTHER berpengaruh negatif signifikan pada expected return. Alokasi Aset progam imbalan pasti dan iuran pasti Dana Pensiun Pemberi Kerja (DPPK) cenderung ke ekuitas dan surat hutang yang lebih tinggi imbal hasil yang didapatkan dibandingkan dengan aset progam Iuran pasti Dana Pensiun Lembaga Keuangan (DPLK) lebih banyak ke deposito yang imbal hasil sudah tetap.
\end{abstract}

\section{PENDAHULUAN}

Perusahaan memiliki karyawan untuk menjalan kegiatan usahanya dan perusahaan wajib memberikan imbalan kerja atas jasa yang diberikan karyawan untuk keberlangsungan dan cita-cita perusahaan dalam mencapai keuntungan perusahaan. Menurut UU RI No 11 Tahun 1992 Tentang Dana Pensiun perusahaan wajib membayar upah atau imbalan atas tenaga yang diberikan karyawannya dan pasca kerja yang sering kita sebut imbalan pensiun. Imbalan pensiun yang diberikan berasal dari 
iuran yang dibayarkan oleh karyawan dan perusahaan menurut Peraturan Pemerintah No. 45 Tahun 2015 tentang Penyelenggaraan Program Jaminan Pensiun.

Dana yang terkumpul dari iuran imbalan pensiun tersebut menjadi aset progam dana pensiun yang dikelola khusus oleh entitas terpisah dari perusahaan. Entitas terpisah tersebut dikelola oleh badan Dana Pensiun yang bisa dikelola oleh perusahaan pemberi kerja yang disebut Dana Pensiun Pemberi Kerja (DPPK) dan juga bisa dikelola oleh lembaga keuangan yang disebut Dana Pensiun Lembaga Keuangan (DPLK). Berdasarkan PSAK 24 tahun
2018 imbalan pasca kerja ada dua jenis yaitu imbalan pasti dan iuran pasti. Imbalan kerja baik tipe imbalan pasti maupun iuran pasti terkumpul dalam aset progam dana pensiun. DPPK dapat mengelola dana dari iuran pasti dan imbalan pasti, sedangkan DPLK hanya dapat mengelola dana dari iuran pasti.

Aset progam dan pensiun yang dikelola oleh DPPK atau DPLK dialokasikan kedalam berbagai investasi yang akan memberikan imbal hasil yang diharapkan (Expected return). Alokasi aset progam dana pensiun menurut data statistik Otaritas Jasa Keuangan (OJK) sebagai berikut:

Tabel 1. Statistik Dana Pensiun per Juli 2019

(dalam miliar rupiah)

\begin{tabular}{clr}
\hline NO & \multicolumn{1}{c}{ ASET DANA PENSIUN } & \multicolumn{1}{c}{$\%$} \\
\hline 1 & Deposito berjangka pada Bank & $26,87 \%$ \\
\hline 2 & Surat Berharga Negara & $23,52 \%$ \\
\hline 3 & Obligasi korporasi yang tercatat di Bursa Efek di Indonesia & $20,83 \%$ \\
\hline 4 & Saham yang tercatat di Bursa Efek di Indonesia & $11,94 \%$ \\
\hline 5 & Reksa Dana & $5,76 \%$ \\
\hline 6 & Penyertaan langsung & $3,50 \%$ \\
\hline 7 & Tanah dan Bangunan di Indonesia & $2,67 \%$ \\
\hline 8 & Tanah di Indonesia & $1,51 \%$ \\
\hline 9 & Sukuk Korporasi yang Tercatat di Bursa Efek di Indonesia & $1,19 \%$ \\
\hline 10 & Bangunan di Indonesia & $0,77 \%$ \\
\hline 11 & Deposito on call pada Bank & $0,51 \%$ \\
\hline 12 & Efek beragun aset & $0,34 \%$ \\
\hline 13 & Sertifikat deposito pada Bank & $0,27 \%$ \\
\hline 14 & Tabungan pada Bank & $0,22 \%$ \\
\hline 15 & MTN (Medium Term Notes) & $0,07 \%$ \\
\hline 16 & Dana investasi real estat berbetuk kontrak investasi kolektif & $0,04 \%$ \\
\hline 17 & Surat berharga yang diterbitkan oleh Bank Indonesia & $0,00 \%$ \\
\hline 18 & Kontrak opsi dan kontrak berjangka efek yang tercatat di Bursa Efek & $0,00 \%$ \\
\hline 19 & di Indonesia & \\
\hline & REPO & $0,00 \%$ \\
\hline
\end{tabular}

Sumber: Data Otoritas Jasa Keuangan yang diolah, 2019

Menurut informasi OJK alokasi dana pensiun paling tertinggi adalah deposito dana berjangka, surat berharga negara, obligasi dan saham dan lainnya. Setiap alokasi investasi aset program dana pensiun mengharapkan imbal hasil yang terbaik dari resiko investasi yang dipilihnya. Menurut penelitian Amir dan Benartzi (1999) menemukan perusahaan 
mengalokasikan aset dana pensiunnya ke investasi ekuitas dan pendapatan tetap untuk mengurangi volatilitas hasil investasi dana pensiun, dan perusahaan besar biasanya mengambil resiko yang tinggi dalam mengelola aset dana pensiunnya dengan mengalokasikannya ke ekuitas, sebaliknya perusahaan yang lebih kecil lebih banyak mengalokasikan ke obligasi supaya mengimbangi beberapa resiko.

Perusahaan dalam menanamkan investasi aset progam dana pensiun perlu memperkirakan expected return yang mendekati actual return supaya kewajiban biaya pensiun di masa depan berkurang menurut Kasaoka (2016). Begitu juga Hwang \& Sarath (2018) menyatakan investor dalam mengevaluasi keakuratan actual return perlu melihat expected return yang dapat menggambarkan pengembalian dalam investasi dana pensiun.

Muhammad Helmi Kamal Lubis saat menjabat presiden direktur Dana Pensiun PT Pertamina tidak mengkaji ulang saat menggunakan dana pensiun untuk membeli saham PT Sugih Energy Tbk (SUGI) yang menyebabkan kerugian negara hingga Rp599,4 miliar (Damanik, 2019). Begitu juga di 2019 terkuak kasus Jiwasraya yang membeli saham gorengan dengan tidak didukung kajian usulan penempatan saham yang memadai. Sebaiknya ketika mengambil keputusan investasi harus mengkaji dahulu tujuan investasi, jangka waktu serta resiko yang ada, sehingga bisa menentukan alokasi investasi yang sesuai dengan imbal hasil yang diinginkan. Pengelolaan dana pensiun harus dilakukan secara berhati hati sebab jika terjadi kesalahan dalam menginvestasikan dana tersebut maka di masa depan perusahaan akan beresiko menanggung kerugian, karena harus membayar kekurangan dana pensiun yang menjadi hak karyawan.

Tujuan dilakukan dari penelitian ini adalah pertama untuk mengetahui apakah alokasi aset program dana pensiun ke ekuitas berpengaruh dalam menetapkan expected return. Kedua, untuk mengetahui apakah alokasi aset program dana pensiun ke surat utang berpengaruh dalam menetapkan expected return. Ketiga, untuk mengetahui apakah alokasi aset program dana pensiun ke deposito berpengaruh dalam menetapkan expected return. Keempat, untuk mengetahui apakah alokasi aset program dana pensiun ke real estate berpengaruh dalam menetapkan expected return. Kelima, untuk mengetahui apakah alokasi aset program dana pensiun ke aset lainnya berpengaruh dalam menetapkan expected return.

Penelitian ini mempunyai kegunaan perusahaan dalam menentukan expected return dengan cara memilih alokasi aset program dana pensiun yang memberikan imbal hasil yang optimal. Expected return yang optimal artinya return yang mendekati imbal hasil yang sebenarnya. Dengan pemilihan alokasi dengan expected return yang optimal diharapkan nantinya dapat mengurangi jumlah beban pensiun yang ditanggung oleh perusahaan. Manfaat kedua dari penelitian ini adalah memberikan informasi bagi karyawan yang bekerja di suatu perusahaan agar dapat mengetahui jumlah imbalan pensiun yang seharusnya didapatkan saat memasuki usia pensiun.

\section{KAJIAN LITERATUR DAN PENGEMBANGAN HIPOTESIS \\ Teori Prospek}

Menurut McDermott (2001) teori prospek adalah teori pengambilan keputusan dalam kondisi risiko. Teori Prospek memberikan alternatif pilihan pengambilan keputusan artinya secara akurat menggambarkan bagaimana orang-orang membuat keputusan. Menurut Hsu dan Chiang (2014), teori prospek menunjukkan bahwa ketika memilih di antara alternatif risiko, individu berperilaku seolah-olah mereka mengevaluasi hasil sebagai perubahan dari titik referensi. Titik referensi biasanya merupakan 
aspek dari keadaan pembuat keputusan saat ini.

Teori prospek dapat menggambarkan perusahaan dalam menentuan besaran nilai expected return atas alokasi aset program dana pensiun. Nilai expected return akan menggambarkan pengembalian imbal hasil atas alokasi aset program dana pensiun, supaya mengurangi biaya pensiun yang ditanggung oleh perusahaan.

\section{Teori State Preference}

Menurut Arrow dan Debreu (1954), teori state preference adalah teori yang mendukung penentuan optimal pada alokasi aset yang terjadi pada kondisi ketidakpastian. Teori ini yang menjadikan awal pemikiran dalam pengembangan alokasi aset program dana pensiun. Menurut OJK (2019), masing-masing perusahaan akan memaksimalkan perencanaannya agar dapat memenuhi kebutuhan karyawannya dimasa depan.

Teori state preference dapat menjelaskan penentuan alokasi atas aset program dana pensiun agar perusahaan dapat mendapatkan imbal hasil yang diharapkan secara optimal. Alokasi aset program dana pensiun dapat dialokasikan ke ekuitas, surat utang, deposito, real estate dan aset lainnya.

\section{Teori Continuous-time Finance}

Menurut Merton (1989), teori continuous-time finance ini merupakan teori yang menjadi jembatan pada teori state preference. Dengan adanya teori ini dapat memaksimalkan pengalokasian karena dapat menjangkau jangka panjang, dinamis serta berkelanjutan. Dengan adanya teori ini yang menjadi jembatan pada teori state preference, menjadikan setiap pekerja yang masih pada usia produktif atau masih bekerja akan melakukan penyisihan dari pendapatan yang didapatkan saat ini untuk dialokasikan dengan tujuan mendapatkan manfaat pada masa depan atau saat individu memasuki usia pensiun.

Menurut continuous-time finance, perusahaan akan menghitung berapa jumlah yang akan disisihkan dari pendapatan untuk iuran pensiun yang akan menjadi hak bagi karyawannya dimasa depan. Menurut PP RI No 45 tahun 2015 Tentang Penyelenggaraan Progam Jaminan Pensiun (2015), pasal 28, besaran iuran yang harus dibayarkan adalah $3 \%$ yaitu $2 \%$ berasal dari perusahaan dan $1 \%$ dipungut dari karyawan.

\section{Imbalan Pascakerja}

Di dalam PSAK 24 tentang Imbalan Kerja, Imbalan pascakerja mempunyai dua jenis program pensiun yaitu program pensiun iuran pasti dan program pensiun manfaat pasti. Pada program pensiun iuran pasti dapat diselenggarakan oleh DPPK dan DPLK, namun untuk program Pensiun Manfaat pasti hanya dapat diselenggarakan oleh DPPK. Berikut merupakan peta imbalan kerja berdasarkan PSAK 24: 


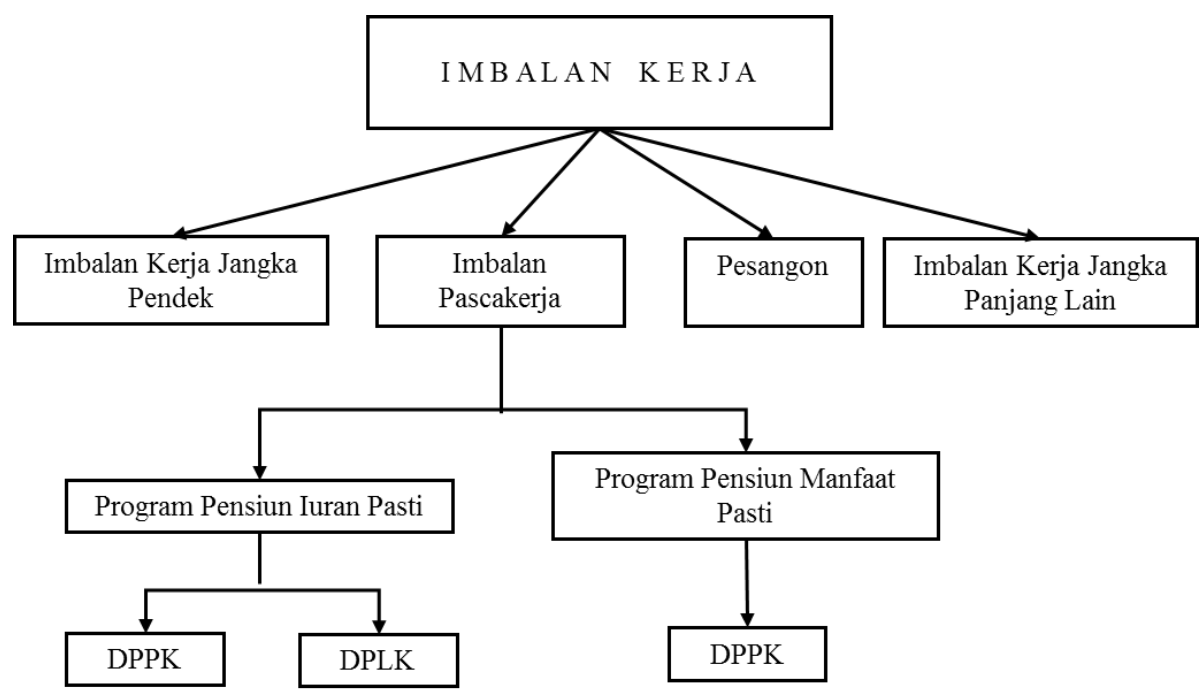

Gambar 1. Peta Imbalan PascaKerja

\section{Alokasi Aset Program Dana Pensiun ke Expected return}

Alokasi dari aset program dana pensiun akan mempengaruhi nilai expected return. Perusahaan yang ada di Indonesia cenderung mengalokasikan aset program dana pensiun kedalam ekuitas, surat utang, deposito, real estate dan aset lainnya. Tentunya perusahaan dalam membuat perencanaan alokasi aset program dana pensiun yang dapat memberikan expected return yang tinggi.

Kasaoka (2016) meneliti tentang perusahaan yang mengalokasikan aset program dana pensiun ke dalam ekuitas akan menetapkan expected return yang tinggi. Hasilnya menunjukkan bahwa pada perusahaan Jepang yang mengadopsi US-GAAP pada tahun 2003-2014, alokasi aset program dana pensiun ke ekuitas menunjukkan pengaruh negatif. Hal ini terjadi ketika sebelumnya harga saham naik perusahaan lebih banyak mengalokasikan aset program dana pensiunnya ke dalam saham. Namun saat itu harga saham turun dan obligasi menawarkan pengembalian yang lebih tinggi. Hasil kedua menujukkan saat perusahaan Jepang mengadopsi J-GAAP pada tahun 20132014, alokasi aset program dana pensiun yang dimasukan kedalam ekuitas memiliki pengaruh yang positif signifikan.

Penelitian yang dilakukan oleh Hwang dan Sarath (2018), yang melakukan penelitian pengaruh alokasi aset program dana pensiun terhadap expected return. Alokasi aset program dana pensiun di masukan ke dalam aset lainnya, ekuitas, real estate, kas dan setara kas dan investasi alternatif. Penelitian dilakukan pada periode 2003-2005 ketika pemantauan aktif dari SEC terhadap pengungkapan expected return, hasilnya menunjukkan bahwa alokasi aset program dana pensiun ke aset lainnya dan real estate tidak signifikan, hal ini terjadi apabila perusahaan mengatur expected return tinggi maka akan menarik perhatian SEC untuk menuntut penjelasan dari penetapan expected return yang tinggi. Untuk varibel lainnya hasillnya menunjukan berpengaruh signifikan. Namun pada tahun 2006-2008 ketika SEC mengurangi pengawasan terhadap pengungkapan expected return hasilnya bahwa semua variable berpengaruh signifikan terhadap expected return. 


\section{Pengembangan Hipotesis}

H1 : Alokasi aset program dana pensiun ke ekuitas berpengaruh terhadap expected return.

H2 : Alokasi aset program dana pensiun ke surat utang berpengaruh terhadap expected return.

H3 : Alokasi aset program dana pensiun ke deposito berpengaruh terhadap expected return.

$\mathrm{H} 4$ : Alokasi aset program dana pensiun ke real estate berpengaruh terhadap expected return.

H5 : Alokasi aset program dana pensiun ke aset lainnya berpengaruh terhadap expected return.

\section{Kerangka Pemikiran}

Teori Prospek sebagai teori dasar pada saat mengambil keputusan dalam memilih investasi yang memberikan hasil yang diinginkan. Dan dalam mengalokasikan investasi untuk mendapatkan hasil yang optimal didukung teori state preference dan karena dana pensiun dilakukan dalam waktu yang panjang maka teori yang mejembatani teori state preference adalah teori continuoustime-finance untuk memaksimalkan alokasi dalam jangka panjang.

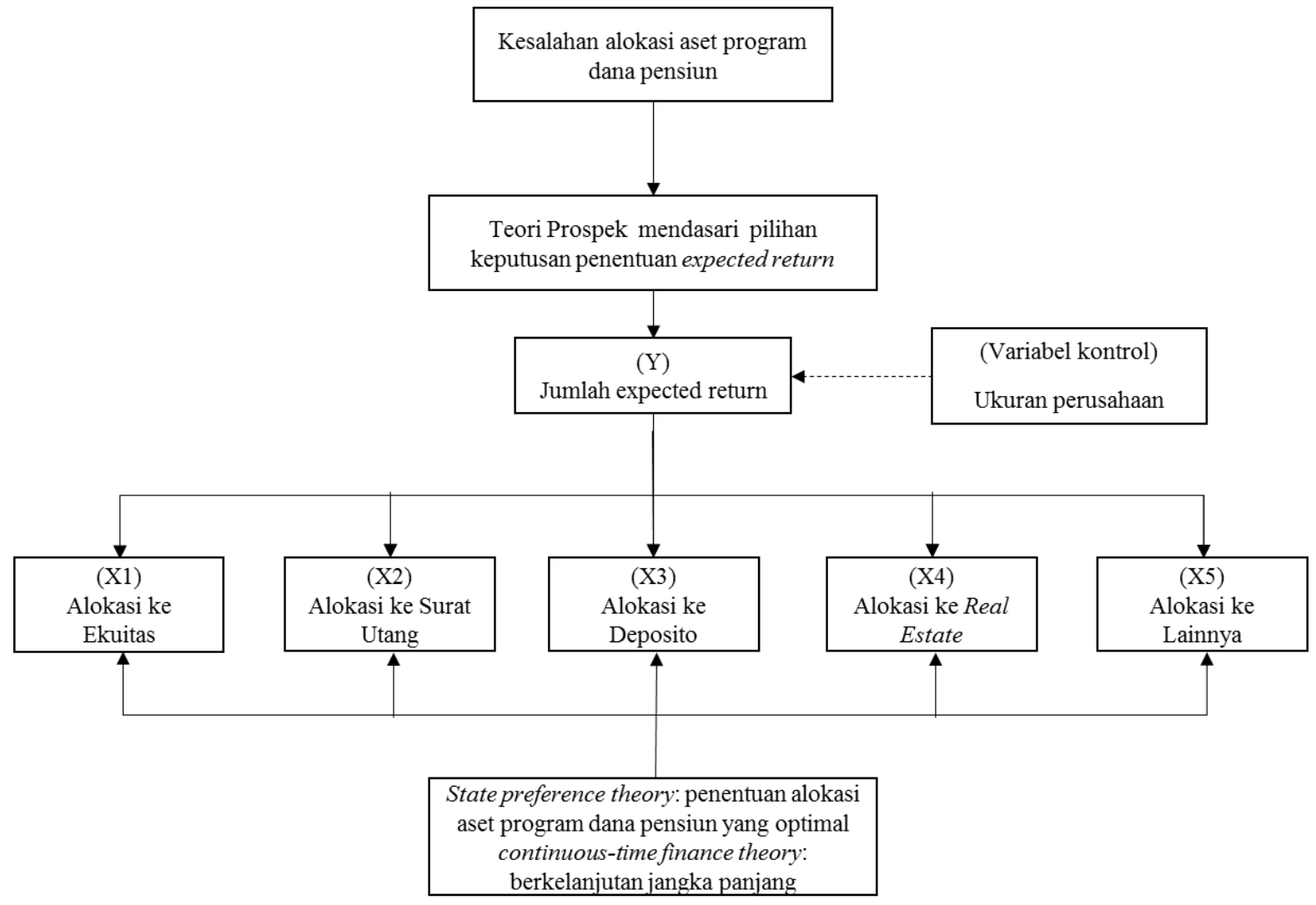

Gambar 2. Kerangka Pemikiran

\section{METODOLOGI PENELITIAN \\ Populasi dan Sampel}

Populasi yang digunakan dalam penelitian adalah seluruh perusahaan yang listed di Bursa Efek Indonesia baik indrustri keuangan dan non keuangan, metode sampel dipilih dengan menggunakan teknik purposive sampling dengan kriteria-kriteria, yaitu pertama perusahaan yang terdaftar di Bursa Efek Indonesia selama tahun 2016 sampai 
2018. Kedua, perusahaan yang mengungkapkan dalam laporan keuangannya, jumlah expected return atau pengembalian yang diharapkan atas alokasi investasi aset dana pension. Ketiga, perusahaan yang mengungkapkan dalam laporan keuangannya, rincian alokasi investasi aset dana pensiun.

\section{Sumber Data}

Sumber data penelitian diperoleh dari Laporan keuangan tahunan perusahaan yang listed di website BEI dan data statistik dana pensiun dan direktori dana pensiun yang dipublikasikan di web site Otoritas Jasa Keuangan (OJK).

\section{Model Penelitian}

Model yang dipakai merujuk salah satu model penelitiannya Hwang and Sarath (2018) yang dipakai dalam penelitian ini adalah sebagai berikut:

$$
\begin{aligned}
\mathrm{ER}= & \alpha+\beta 1 \text { EKUITAS }+\beta 2 \mathrm{SU}+\beta 3 \mathrm{DEPO}+\beta 4 \mathrm{RE} \\
& +\beta 5 \text { OTHER }+\beta 6 \text { SIZE }+\varepsilon(1)
\end{aligned}
$$

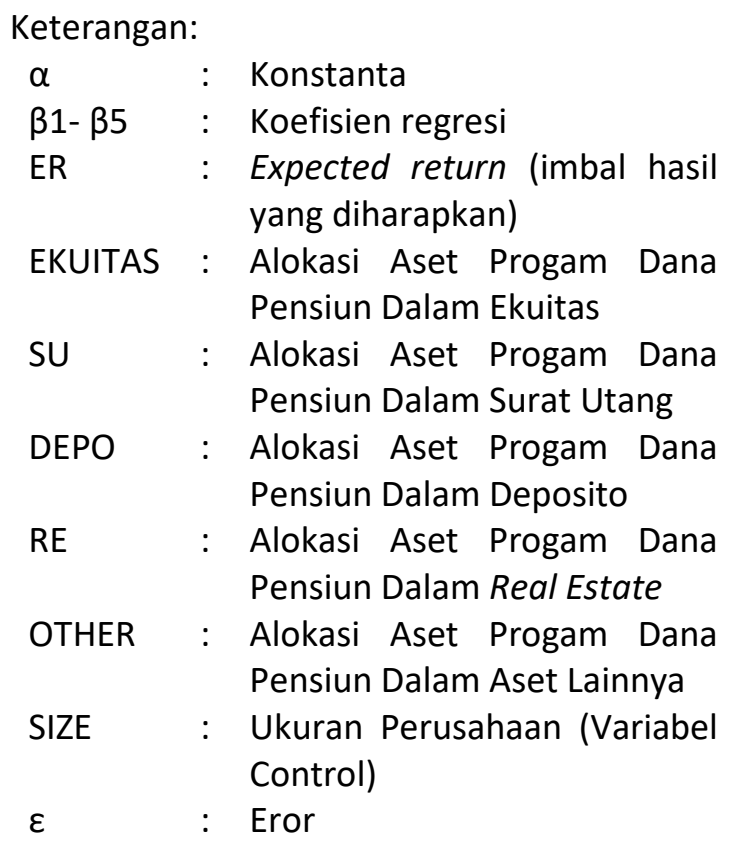

Variabel Penelitian dan Pengukuran Variabel

Definisi variabel dependen dan independen serta pengukurannya dijelaskan sebagai berikut:

\section{Variabel dependen}

Expected return (imbal hasil yang diharapkan)

Pengukuran expected return dari penelitiannya Hsu and Chiang (2014) dapat dihitung dengan cara sebagai berikut:

Expected return $=$ Actual return on plan assets - Deferred gain atau,

Expected return $=$ Actual return on plan assets + Deferred loss

\section{Variabel Indepeden}

Ekuitas adalah jumlah alokasi aset progam dana pensiun dari saham, reksadana, dan penyertaan langsung. Surat Utang (SU) adalah jumlah alokasi aset progam dana pensiun dari surat berharga negara, Obligasi korporasi, Sukuk korporasi, dan Medium Term Notes (MTN). DEPO adalah jumlah alokasi aset dana pensiun dari deposito berjangka, deposito on call, sertifikat deposito pada bank. Real Estate (RE) adalah jumlah alokasi aset progam dana pensiun dari tanah dan bangunan di Indonesia. Lainnya (Other) adalah jumlah dana syariah, derivatif, kas dan setara kas yang dikelompokkan menjadi 1 variabel yaitu other dialokasikan dari aset progam dana pensiun. Dimasukkan dalam satu variabel Other dikarenakan sangat sedikit Dana Pensiun mengalokasikan ke dana syariah, kas dan setara kas. Size adalah ukuran perusahaan dari LN Total Aset sebagai varibel kontrol.

\section{Pengujian Asumsi Klasik}

Uji Normalitas

Uji Normalitas memakai hasil perhitungan Kolmogorof Smirnov Test, hasilnya menunjukkan data terdistribusi normal dari model yang digunakan Unstandardized Residual menunjukkan nilai signifikansinya 
sebesar 0,2 yang menyatakan terdistribusi normal karena diatas 0,1 sehingga bisa dilakukan regresi normal (Ghozali, 2018) (lihat lampiran).

Uji Non-Heteroskedastisitas

Untuk menguji heteroskedasitas dilakukan dengan melihat grafik plot nilai prediksi variabel dependen ialah ZPRED dengan residual SPRED dan hasilnya tidak terjadi heterokedastisitas terlihat hasilnya titiktitiknya menyebar tidak tertentu dan tidak membentuk suatu pola tertentu Ghozali (2018) (lihat lampiran).

Uji Multikolinearitas

Menguji adanya multikolineritas dilihat

dari Variance Inflantion Factor (VIF)

menunjukkan variabel EKUITAS, SU, DEPO, RE, OTHER tidak terjadi multikolineritas karena semua nilai VIF nya lebih kecil dari 10 Ghozali (2018) (lihat lampiran).

\section{HASIL DAN PEMBAHASAN}

Metode sampel dipilih dengan menggunakan teknik purposive sampling menghasilkan 93 data penelitian dari 31 perusahaan yang mengungkapkan sesuai kriteria kriteria yang dibutuhkan seperti di Tabel 2. Ini menunjukkan masih banyak perusahaan belum mengungkap progam pensiun dan expected return dan rincian alokasi investasi aset progam dana pensiun dalam laporan keuangan.

Tabel 2. Sampel data observasi

\begin{tabular}{lr}
\hline \multicolumn{1}{c}{ Keterangan } & Jumlah \\
\hline Perusahaan yang terdaftar di BEI, berturut-turut dari tahun 2016, 2017 dan 2018 & 538 \\
\hline Jumlah tahun penelitian & 3 \\
\hline Jumlah data & 1.614 \\
\hline Jumlah perusahaan yang tidak mengungkapkan program pensiun & $(363)$ \\
\hline $\begin{array}{l}\text { Jumlah perusahaan yang tidak mengungkapkan expected return dalam laporan } \\
\text { keuangan }\end{array}$ & \\
\hline $\begin{array}{l}\text { Jumlah perusahaan yang tidak mengungkapkan rincian alokasi investasi aset dana } \\
\text { pensiun }\end{array}$ & (1.134) \\
\hline Jumlah data penelitian & 93 \\
\hline
\end{tabular}

Berdasarkan Tabel 3, hasil uji $R^{2}$ menunjukkan nilai Adjusted R Square sebesar 75,7 \% yang artinya bahwa alokasi alokasi investasi dana pensiun kedalam ekuitas, surat utang, deposito, real estate dan Other menjelaskan expected return sebesar 75,7\% dan sisanya sebesar $24,3 \%$ dijelaskan oleh faktor lainnya yang tidak diteliti dalam penelitian ini.

Tabel 3. Hasil Uji $\mathbf{R}^{2}$

\section{Model Summary ${ }^{b}$}

\begin{tabular}{ccccc}
\hline Model & $\mathrm{R}$ & R Square & $\begin{array}{c}\text { Adjusted R } \\
\text { Square }\end{array}$ & $\begin{array}{c}\text { Std. Error of } \\
\text { the Estimate }\end{array}$ \\
\hline 1 & $.879^{\mathrm{a}}$ & 0.773 & 0.757 & 1.2301305 \\
\hline Sumber: Data diolah & &
\end{tabular}


Analisis pengujian pengaruh variabel alokasi investasi aset progam dana pensiun pada expected return berdasarkan hasil uji t dalam tabel 4 menunjukkkan semua variabel bepengaruh signifikan positif, tetapi hanya variabel Other alokasi aset progam dana pensiun yang memiliki arah negatif. Dan model regresi berganda yang terbentuk sebagai berikut:

$E R=-3.639+0.059$ EKUITAS +0.077 SU + 0.059 DEPO -0.075 OTHER + 0.660 SIZE

Tabel 4. Hasil Uji Statistik t

\begin{tabular}{c|l|r|r|c}
\hline \multicolumn{5}{c}{ Coefficients $^{\mathbf{a}}$} \\
Model & & \multicolumn{1}{c}{ B } & T & Sig. \\
\hline 1 & (Constant) & -3.639 & $-2,996$ & 0.004 \\
\hline & EKUITAS & 0.059 & 2,106 & 0.038 \\
\hline & SU & 0.077 & 2.647 & 0.010 \\
\hline & DEPO & 0.059 & 2.078 & 0.041 \\
\hline & RE & 0.181 & 5.064 & 0.000 \\
\hline & OTHER & -0.075 & $-1,985$ & 0.050 \\
\hline & SIZE & 0.660 & 8.138 & 0.000 \\
\hline
\end{tabular}

Sumber: Data diolah

Dana Pensiun yang dialokasikan ke Ekuitas dikelola oleh DPPK sebanyak 86\% dalam Tabel 5 hasil dari data yang di peroleh menunjukkan perusahaan berharap expected return yang tinggi atas alokasi ekuitas dan sesuai dalam hasil data OJK pada lampiran laporan aset neto dana pensiun. Penelitian ini sejalan dengan penelitian Hwang dan Sarath (2018) menyatakan investasi dana pensiun yang dialokasikan ke ekuitas berpengaruh signifikan terhadap expected return, berarti semakin tinggi alokasi investasi aset progam dana pensiun kedalam ekuitas maka semakin tinggi imbal hasil yang diharapkan.

Hasil uji t menunjukkan alokasi dana pensiun surat utang berpengaruh signifikan terhadap expected return ini bisa terlihat dari aset progam dana pensiun yang dialokasikan ke surat utang oleh DPPK sekitar $85 \%$ dan dan DPLK 58\% (lihat Tabel 5) dalam sampel penelitian dan hasil data OJK dalam lampiran aset neto dana pensiun menunjukkan alokasi dana pensiun ke surat hutang merupakan terbanyak kedua sesudah alokasi ekuitas di
DPPK dan DPLK sesudah alokasi dana pensiun ke deposito.

Menurut hasil uji $\mathrm{t}$ aset progam dana pensiun yang dialokasikan ke deposito menunjukkan berpengaruh signifikan, terlihat dari Tabel 1 menunjukkan alokasi dana pensiun ke deposito berjangka menduduki no 1 dan menurut data sampel dalam tabel 5 menunjukkan DPLK paling banyak mengalokasikan dana ke deposito sebanyak $78 \%$, sedangkan DPPK juga cukup banyak mengalokasikan ke deposito. Dana pensiun yang dialokasikan ke deposito mempunyai imbal hasil yang tetap dan pasti, sehingga banyak dana pensiun dialokasikan ke deposito untuk mengamankan tingkat pengembalian karena tingkat kepastian pengembaliannya lebih tinggi.

Menurut Sari (2019) investasi di Indonesia yang berasal dana pensiun dialokasikan ke infrastruktur sebesar 1 sampai $10 \%$ yang bisa menghasilkan imbal hasil sebesar 13\%, ini menunjukkan investasi dibidang infrastruktur atau real estate 
Dwi Jaya Kirana: Penerapan Portofolio Investasi ...

menggiurkan, terlihat dari hasil uji $\mathrm{t}$ menunjukkan alokasi investasi aset progam dana pensiun yang dialokasikan ke real estate berpengaruh signifikan, yang berarti jika perusahaan dana pensiun mengalokasikan ke Real estate akan meningkatkan expected return-nya dan ini sejalan dengan hasil penelitian Hwang dan Sarath (2018).

Hasil Uji $\mathrm{t}$ menunjukkan alokasi dana pensiun Other yang berisi dari dana syariah, derivatif, kas dan setara kas berpengaruh signifikan ke arah negatif, yang berarti alokasi dana pensiun pada investasi lainnya akan mengurangi ekspektasi imbal hasilnya karena sifatnya untuk jangka pendek dan bersifat liquid. Biasanya dilakukan oleh dana pensiun yang sebentar lagi harus membayar kewajiban dana pensiun karyawan dalam jangka pendek sehingga ekspektasinya tidak mengharapkan imbal hasil yang tinggi.

Size sebagai variabel kontrol menunjukkan berpengaruh signifikan, ini menggambarkan semakin besar ukuran perusahaan semakin besar juga ekspektasi imbal hasil dalam pengalokasian dana pensiunnya. Hasil penelitian dalam Amir \& Benartzi (1999) yang menyatakan ukuran perusahaan yang besar cenderung mengalokasikan aset progam dana pensiunnya ke Ekuitas, sedangkan perusahaan kecil mengalokasikan aset progam dana pensiunnya ke obligasi atau surat utang yang volatilitasnya kecil, karena perusahaan kecil tidak mau mengambil resiko dalam pengelolaan investasi dana pensiunnya.

Tabel 5. Alokasi Aset Program Dana Pensiun

\begin{tabular}{c|c|c|c|c|c}
\hline & Ekuitas & Surat Utang & Deposito & Real Estate & Lainnya \\
\hline DPPK & 0,86 & 0,85 & 0,62 & 0,35 & 0,67 \\
\hline DPLK & 0,51 & 0,58 & 0,78 & 0,20 & 0,47 \\
\hline
\end{tabular}

Sumber: olahan hasil data statistik dana pensiun tahun 2016-2018

Hasil dari Tabel 5 Aset progam dana pensiun menunjukkan alokasi dana pensiun DPPK lebih banyak ke Ekuitas surat utang dan deposito, Kecenderungan DPPK ke ekuitas $86 \%$ dan surat hutang $85 \%$ karena imbal hasil yang diharapkan lebih tinggi sehingga mengurangi biaya pensiun yang dibayarkan ke karyawan karena tipe program dana pensiun DPPK adalah imbalan pasti dan iuran pasti, sesuai dengan data di lampiran (Statistik Dana Pensiun Periode Juli 2019). Tapi DPLK lebih banyak mengalokasikan ke Deposito $78 \%$ dari pada ekuitas, surat hutang dikarenakan DPLK hanya memiliki progam luran Pasti, karena pihak DPLK tidak ada berkewajiban dan tidak ada tuntutan dalam memenuhi imbalan pasti hanya memberikan sesuai iuran yang dibayarkan dan pengembangan yang didapat saja.

\section{PENUTUP}

Hasil penelitian dari semua perusahaan listed di Indonesia yang mengungkapkan alokasi aset progam dana pensiun menunjukkan semua variabel alokasi mempengaruhi expected return kecuali variabel Other yang mempunyai arah negatif dikarenakan variabel Other adalah alokasi aset progam dana pensiun ke dana syariah, derivatif, kas dan setara kas yang memberikan return yang rendah dibandingkan yang lain sehingga mengurangi jumlah ekspektasi imbal hasil.

Semua perusahaan listed di BEI yang mengungkapkan alokasi aset dana pensiun serta Expected return selama 3 tahun dari tahun 2016 sampai dengan 2018 sebanyak 31 perusahaan. Ini menunjukkan sangat sedikit perusahaan yang mengungkapkannya didalam laporan keuangan sedangkan informasi alokasi aset progam dana pensiun dibutuhkan juga buat karyawan yang nantinya menerima manfaat dari dana pensiun dan imbal hasil yang diharapkan, supaya tidak disalahgunakan, seperti kejadian Pertamina yang 
menyalahgunakan aset progam ke alokasi yang salah ditahun 2014-2015 (“Kasus Dana Pensiun Pertamina, Hukuman Edward Diperberat Jadi 15 Tahun," n.d.), sehingga disarankan dari temuan penelitian ini adalah diharapkan perusahaan mengungkapkan tambahan informasi berkaitan alokasi aset progam dana pensiun dan Expeted return dalam catatan laporan keuangannya.

\section{REFERENSI}

Amir, E., \& Benartzi, S. (1999). Accounting Recognition and the Determinants of Pension Asset Allocation. Journal of Accounting, Auditing \& Finance, 14(3), 321-343.

https://doi.org/10.1177/0148558X99014 00309

Arrow, K. J., \& Debreu, G. (1954). Existence of an Equilibrium for a Competitive Economy. Journal of Econometric Society, 22(9), 265-290. https://doi.org/10.1017/СВ0978110741 5324.004

Ghozali, I. (2018). Aplikasi Analisis Multivariate dengan Program IBM SPSS 25 (Edisi 9). Semarang: Universitas Diponegoro.

Hsu, P., Bay, E., \& Chiang, Y. (2014). Using Prospect Theory To Explain The Setting Of The Expected Rate Of Return On Pension Assets. 30(5), 1457-1464.

Hwang, S., \& Sarath, B. (2018). Disclosure of pension asset allocation and expected rate of return management. Asian Review of Accounting, 26(2), 182-207. https://doi.org/10.1108/ARA-06-20170096

Kasaoka, E. (2016). The Expected Rate of Return on Plan Assets and Pension Asset Allocation. Review of Integrative Business and Economics Research, 5(4), 249-270.

Kasus Dana Pensiun Pertamina, Hukuman Edward Diperberat Jadi 15 Tahun. (n.d.).
Retrieved November 6, 2019, from https://www.idntimes.com/news/indone sia/sunariyah/kasus-dana-pensiunpertamina-hukuman-edward-diperberatjadi-15-tahun/full

McDermott, R. (2001). Risk-Taking in International Politics: Prospect Theory in American Foreign Policy. In The American Political Science Review (Vol. 94). https://doi.org/10.2307/2585915

Merton, R. C. (1989). On the Application of the Continuous-Time Theory of Finance to Financial Intermediation and Insurance *. 14(52), 225-261.

OJK. (2019). Program Pensiun Seri Literasi Keuangan Perguruan Tinggi. In Otoritas Jasa Keuangan (Buku 6). Jakarta: Otoritas Jasa Keuangan.

Peraturan Pemerintah No. 45 Tahun 2015 tentang Penyelenggaraan Program Jaminan Pensiun. , (2015).

PP RI No 45 tahun 2015 Tentang Penyelenggaraan Progam Jaminan Pensiun. , (2015).

PSAK 24 tahun 2018.

Sari, F. (2019). Return menggiurkan, dana pensiun dan asuransi jiwa masuk pembiayaan infrastruktur. Retrieved from https://keuangan.kontan.co.id/news/ret urn-menggiurkan-dana-pensiun-danasuransi-jiwa-masuk-pembiayaaninfrastruktur

Statistik Dana Pensiun Periode Juli 2019. (2019b). Retrieved from Otoritas Jasa Keuangan website: https://www.ojk.go.id/id/kanal/iknb/dat a-dan-statistik/danapensiun/Pages/Statistik-Dana-PensiunPeriode-Juli-2019.aspx

UU RI No 11 Tahun 1992 Tentang Dana Pensiun. , (1992). 
Dwi Jaya Kirana: Penerapan Portofolio Investasi ...

\section{Lampiran}

\section{Laporan Aset Neto Dana Pensiun}

Per Juli 2019

(dalam Miliar Rupiah)

\begin{tabular}{|c|c|c|c|c|}
\hline No & Laporan Aset Neto & DPPK-PPMP & DPPK-PPIP & DPLK-PPIP \\
\hline 1 & Tabungan pada Bank & 292 & 187 & 110 \\
\hline 2 & Deposito on call pada Bank & 733 & 163 & 506 \\
\hline 3 & Deposito berjangka pada Bank & 17.310 & 4.865 & 51.341 \\
\hline 4 & Sertifikat deposito pada Bank & 21 & 95 & 028 \\
\hline 5 & Surat berharga yang diterbitkan oleh Bank Indonesia & & & - \\
\hline 6 & Surat Berharga Negara & 39.807 & 8.366 & 16.176 \\
\hline 7 & Saham yang tercatat di Bursa Efek di Indonesia & 21.681 & 7.073 & 3.920 \\
\hline 8 & Obligasi korporasi yang tercatat di Bursa Efek di Indonesia & 38.771 & 7.639 & 10.585 \\
\hline 9 & Sukuk Korporasi yang Tercatat di Bursa Efek di Indonesia & 1.905 & 216 & 1.143 \\
\hline 10 & Reksa Dana & 10.244 & 2.441 & 3.086 \\
\hline 11 & MTN & 54 & 63 & 73 \\
\hline 12 & Efek beragun aset & 603 & 263 & 51 \\
\hline 13 & Dana investasi real estat berbetuk kontrak investasi kolektif & 90 & 20 & - \\
\hline 14 & Kontrak opsi dan kontrak berjangka efek yang tercatat di Bursa Efek di Indonesia & - & - & - \\
\hline 15 & REPO & - & - & - \\
\hline 16 & Penyertaan langsung & 8.138 & 1.442 & - \\
\hline 17 & Tanah di Indonesia & 3.777 & 352 & - \\
\hline 18 & Bangunan di Indonesia & 1.558 & 554 & - \\
\hline 19 & Tanah dan Bangunan di Indonesia & 7.104 & 169 & 22 \\
\hline & \begin{tabular}{|c|c|} 
TOTAL INVESTASI \\
\end{tabular} & 152.087 & 33.909 & 87.638 \\
\hline
\end{tabular}

DPPK-PPMP = Dana Pensiun Pemberi kerja-Progam Pensiun Manfaat pasti

DPPK- PPIP = Dana Pensiun Pemberi kerja-Progam Pensiun luran Pasti

DPLK-PPIP = Dana Pensiun Lembaga Keuangan-Progam Pensiun luran Pasti

Sumber : Statistik Dana Pensiun Periode Juli 2019

Model Summary

\begin{tabular}{|c|c|c|c|c|c|c|c|c|c|c|}
\hline \multirow[b]{2}{*}{ Model } & \multirow[b]{2}{*}{$\mathrm{R}$} & \multirow[b]{2}{*}{ R Square } & \multirow[b]{2}{*}{$\begin{array}{l}\text { Adjusted R } \\
\text { Square }\end{array}$} & \multirow[b]{2}{*}{$\begin{array}{l}\text { Std. Error of } \\
\text { the Estimate }\end{array}$} & \multicolumn{5}{|c|}{ Change Statistics } & \multirow[t]{2}{*}{$\begin{array}{l}\text { Durbin- } \\
\text { Watson }\end{array}$} \\
\hline & & & & & $\begin{array}{l}\text { R Square } \\
\text { Change }\end{array}$ & F Change & df1 & $\mathrm{df} 2$ & $\begin{array}{l}\text { Sig. F } \\
\text { Change }\end{array}$ & \\
\hline 1 & $\begin{array}{r}879 \\
\text { a }\end{array}$ & ,773 & ,757 & 1,2301305 & ,773 & 48,676 & 6 & 86 & ,000 & 2,537 \\
\hline
\end{tabular}

a. Predictors: (Constant), SIZE, DEPO, RE, EKUITAS, SU, OTHER

b. Dependent Variable: ERR 
JIAFE (Jurnal Ilmiah Akuntansi Fakultas Ekonomi)

Vol. 5 No. 2, Des. 2019, Hal. 131-144

https://journal.unpak.ac.id/index.php/jiafe

P-ISSN: 2502-3020, E-ISSN: 2502-4159

\begin{tabular}{|c|c|c|c|c|c|c|}
\hline \multirow{2}{*}{\multicolumn{2}{|c|}{ Model }} & \multirow[b]{2}{*}{ Sum of Squares } & \multicolumn{4}{|l|}{ ANOVA $^{a}$} \\
\hline & & & Df & Mean Square & $\mathrm{F}$ & Sig. \\
\hline \multirow[t]{3}{*}{1} & Regression & 441,944 & 6 & 73,657 & 48,676 &, $000^{\mathrm{b}}$ \\
\hline & Residual & 130,137 & 86 & 1,513 & & \\
\hline & Total & 572,081 & 92 & & & \\
\hline
\end{tabular}

a. Dependent Variable: ERR

b. Predictors: (Constant), SIZE, DEPO, RE, EKUITAS, SU, OTHER

\begin{tabular}{|c|c|c|c|c|c|c|c|c|c|}
\hline \multirow[b]{3}{*}{ Model } & \multicolumn{7}{|c|}{ Coefficients $^{\mathrm{a}}$} & & \\
\hline & \multicolumn{2}{|c|}{$\begin{array}{l}\text { Unstandardized } \\
\text { Coefficients }\end{array}$} & \multirow{2}{*}{$\begin{array}{c}\text { Standardized } \\
\text { Coefficients } \\
\text { Beta }\end{array}$} & \multirow[t]{2}{*}{$\mathrm{t}$} & \multirow[t]{2}{*}{ Sig. } & \multicolumn{2}{|c|}{$\begin{array}{l}95,0 \% \text { Confidence } \\
\text { Interval for B }\end{array}$} & \multicolumn{2}{|c|}{$\begin{array}{l}\text { Collinearity } \\
\text { Statistics }\end{array}$} \\
\hline & B & Std. Error & & & & $\begin{array}{l}\text { Lower } \\
\text { Bound }\end{array}$ & $\begin{array}{l}\text { Upper } \\
\text { Bound }\end{array}$ & Tolerance & VIF \\
\hline 1 (Constant) & $-3,639$ & 1,215 & & $-2,996$ & ,004 & $-6,053$ & $-1,224$ & & \\
\hline EKUITAS & ,059 & ,028 & 126 & 2,106 & ,038 & ,003 & 115 & 738 & 1,355 \\
\hline SU & ,077 & ,029 & 181 & 2,647 & 010 & ,019 & 136 & ,565 & 1,771 \\
\hline DEPO & ,059 & ,028 & ,128 & 2,078 & ,041 & ,003 & 115 & ,700 & 1,429 \\
\hline $\mathrm{RE}$ & ,181 & ,036 & ,362 & 5,064 & ,000 & 110 & ,252 & ,518 & 1,930 \\
\hline OTHER &,- 075 & ,038 &,- 157 & $-1,985$ & ,050 &,- 150 & ,000 & ,422 & 2,371 \\
\hline SIZE & ,660 & ,081 & ,530 & 8,138 & ,000 & ,499 & ,821 & ,624 & 1,602 \\
\hline
\end{tabular}

a. Dependent Variable: ERR

One-Sample Kolmogorov-Smirnov Test

Unstandardized

Residual

\begin{tabular}{ccc}
\hline \multirow{2}{*}{$N$} & & 93 \\
\hline \multirow{2}{*}{ Normal Parameters $^{\mathrm{a}, \mathrm{b}}$} & Mean &, 0000000 \\
\cline { 2 - 3 } & Std. Deviation & 1,18934126 \\
\hline \multirow{2}{*}{ Most Extreme Differences } & Absolute &, 075 \\
\cline { 2 - 3 } & Positive &, 040 \\
\cline { 2 - 3 } & Negative &,- 075 \\
\hline Test Statistic & &, 075 \\
\hline Asymp. Sig. (2-tailed) &, $200^{\text {c,d }}$ \\
\hline
\end{tabular}




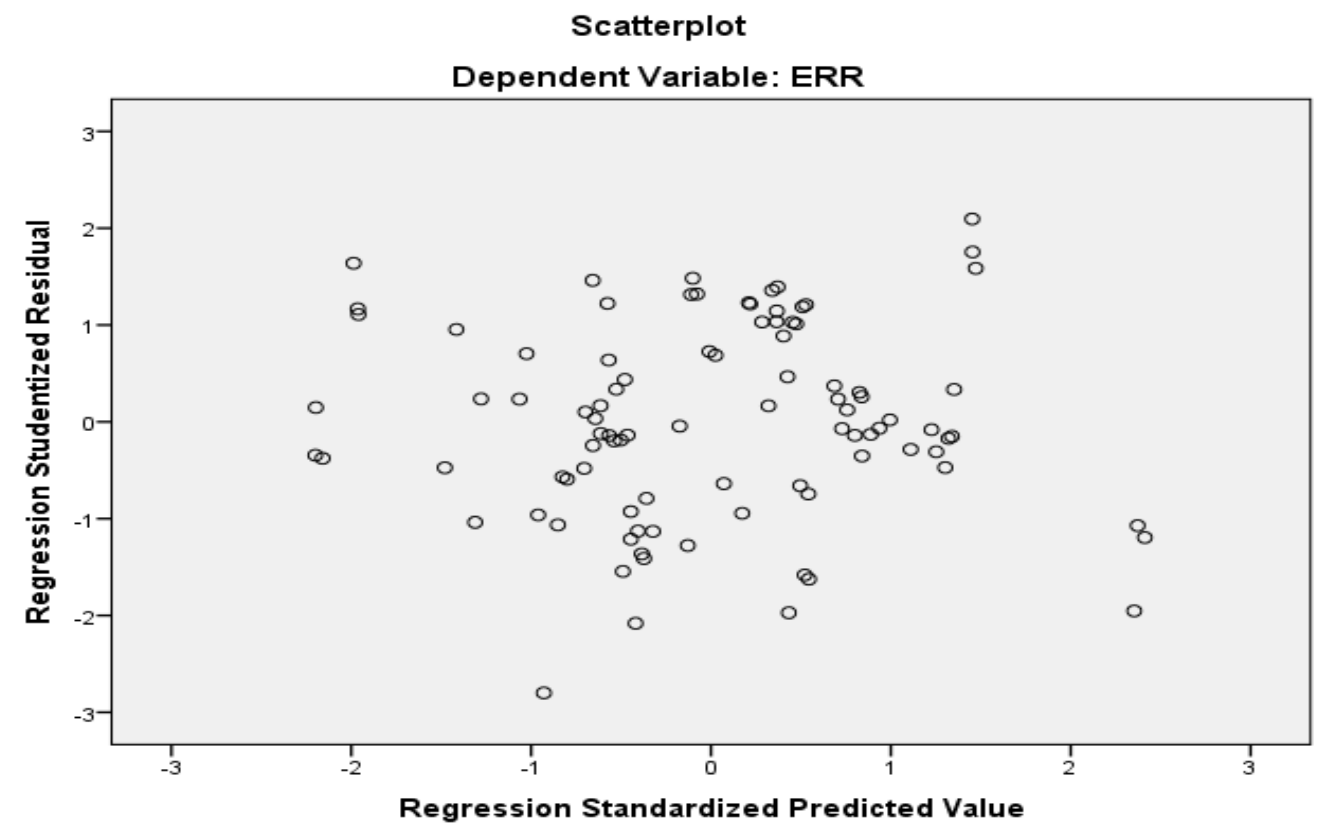

